\title{
Impact of Flexible Polyurethane Foam Cocoon on Premature Babies of Mothers with Pathologic Pregnancies
}

\begin{abstract}
GEORGETA NODITI*, GEORGE NODITI'2, DANIELA IACOB³*, DORU ANASTASIU1', DIANA ANASTASIU1', ADRIAN GLUHOVSCHI ${ }^{1}$ 'Victor Babes University of Medicine and Pharmacy, Department XII, Obstetrics and Gynecology and Neonatology, Bega Clinics, 2 Eftimie Murgu Sq., 300041,Timisoara, Romania

2Victor Babes University of Medicine and Pharmacy, Department of Surgery II, Emergency County Hospital Timisoara, 2 Eftimie Murgu Sq., 300041,Timisoara, Romania

Proper positioning of premature babies resulting from different maternal chronic conditions before pregnancy and hypertension induced during pregnancy can promote normal balanced development with maximizing the sleeping conditions and minimizing the gastric reflux. We conducted a retrospective study on data from Bega Clinics - Obstetrics and Gynecology and Neonatology for 2012-2013 about premature babies of mothers with pathologic pregnancies. Part of the newborns was positioned in a flexible polyurethane foam cocoon and clinical observations on sleeping states and the presence of gastric reflux were noted. In our study, 453 (10.5\%) cases of women with different pathological conditions out of 4,312 cases were encountered. Most of them (48\%) had a diagnosis of chronic hypertension, followed by chronic renal diseases (34\%). Hypertension developed during pregnancy for both years, happened in 340 (7.88\%) cases. Severe forms of hypertension were noted in $57.05 \%$ of them. Incidence of preterm birth babies was $11.22 \%$ (484 cases), of which 12 cases (8.67\%) resulted from pregnancies with different forms of hypertension. Clinical observations stated that sleeping quietly and awake and quiet have increased the most when compared with babies positioned in the cocoon (44 babies) compared with babies (45) out of cocoons. Only 8 (18.2\%) babies positioned in the cocoon experienced gastric reflux comparatively with 41 babies that were positioned in regular conditions.
\end{abstract}

Keywords: polyurethane foam, cocoon, preterm baby, pathologic pregnancy

Chronic diseases can influence the course of pregnancy and may have lasting effects that manifest at and after birth [1]. Some chronic conditions such as diabetes, thyroid disease, seizure disorders, and kidney disease can have adverse outcomes for pregnant woman such as gestational hypertension, preeclampsia, and maternal mortality [2]. In addition, chronic illness can have adverse outcomes on infants, including premature births, intrauterine growth restriction, and neonatal mortality [35].

Women who have hypertension during pregnancy or who develop pre-eclampsia (high blood pressure with protein in the urine or other organ systems involvement, or both) can develop serious complications. Potential complications for the mother are worsening of preeclampsia, development of seizures and eclampsia, HELLP syndrome (haemolysis, elevated liver enzymes and low platelet count), detachment of the placenta, liver failure, renal failure, and difficulty breathing because of fluid in the lungs $[6,7]$.

Premature infants are at risk for developmental delays. Due to immaturity, they often lack adequate muscle tone and are at risk for developing abnormal movement patterns as well as skeleton deformation [8]. Some delays are related to improper body mechanics rather than neurological impairment.

Proper position of premature infants may promote normal motor development while minimizing development of abnormal movement patterns. Craft work and commercial products are available in different countries to assist the positioning of the newborn and promote postural stability and motion of flexion and semi-flexion positions.
This study aimed to analyze the impact of positioning of the premature newborn by means of flexible polyurethane foam cocoon aiming at its application in neonatal intensive care units.

\section{Experimental part}

Materials and methods

Data from Bega Clinics-Obstetrics and Gynecology and Neonatology related to years 2012-2013 were obtained by analyzing observation sheets, registers of birth, caesarean sections sheets and registers of newborn neonatology department.

Indicators that have been took into account were: number of chronic diseases before pregnancy, number of cases of hypertension induced during pregnancy, total number of births, number of prematures, weight at birth, management of hypertensive disorders in pregnancy delivery method.

In case of hypertension induced by pregnancy, the values $\geq 140 \mathrm{~mm} \mathrm{Hg}$ for systolic blood pressure, and $\geq 90 \mathrm{mmHg}$ for diastolic blood pressure measured for the first time during pregnancy occurred after 20 weeks of amenorrhea in a normotensive patients have been used for diagnostic.

In the intensive care unit of Neonatology, part of the newborns was positioned in a flexible polyurethane foam cocoon that has been donated to the clinic by a NGO. The cocoon allows baby to lie on his back in a semi-foetal position. It includes a Tummy Band which retains baby in place, keeps him or her in the correct position.

Each newborn was observed for three days in six states: sleeping quietly; sleeping in activity; transition when awake and active; awake and quiet; annoyed, or crying. The results

*email: george.noditi@gmail.com, Phone: 0735311639; danielariacob@yahoo.com, Phone: 0742558574 


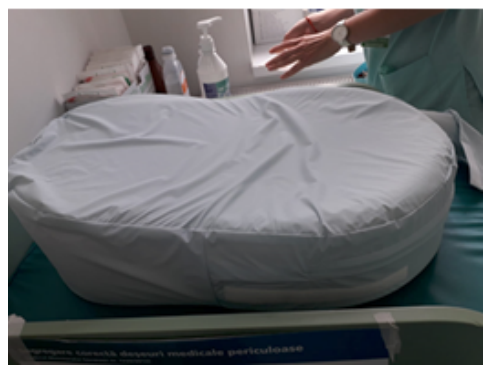

Table 1

WOMEN PATHOLOGICAL CONDITIONS BEFORE PREGNANCY IN THE STUDIED YEARS

\begin{tabular}{|l|l|l|l|}
\hline Pathological condition & No cases/2012 & N0 cases/2013 & Total cases (\%) \\
\hline Chronic hypertension & 107 & 112 & 219 \\
\hline Diabetes & 20 & 22 & 44 \\
\hline Obesity (BMI >30) & 17 & 17 & 34 \\
\hline Chronic renal disease & 79 & 77 & 156 \\
\hline
\end{tabular}

were compared with newborns of the same weight and delivery time. The reflux frequency was also noted.

\section{Results and discussions}

Total number of births was 2,117 for 2012 and 2,195 for 2013 , irrespectively 4,312 for both years.

Number of women with pathological conditions before pregnancy is detailed in table 1, as well as cumulative per both years.

In total there were 453 cases of women with different pathological conditions. Figure 2 is showing the distribution of women pathological conditions before pregnancy.

It is observed that chronic hypertension followed by chronic renal diseases were the most frequent.

Considering the hypertension developed during pregnancy in 2012 a number of 202 (9.54\%) were diagnosed. In 2013, a number of $138(6.28 \%)$ developed hypertension. For both years, 340 (7.88\%) pregnantwomen had induced hypertension.

We could notice different forms of pregnancy-induced hypertension as following:

$-194(57.05 \%)$ severe

- $87(25.58 \%)$ mild and medium

$-3(9.11 \%)$ preeclampsia

-14 (4.11\%) HELLP syndrome

-14 (4.11\%) premature detachment of a normally inserted placenta (PDNIP)

Figure no 3 is showing the distribution of pregnancyinduced hypertension forms. More than half were re

From the group of mothers with induced hypertension during pregnancy 351 newborns were delivered, out of which 340 with single fetus and 11 of multiple fetuses: 4 twins and one triplet.

Management of hypertensive disorders in pregnancy at or near term (from 34 weeks onwards) has been a planned early delivery by induction of labour or caesarean section.
Maternal pathology before pregnancy

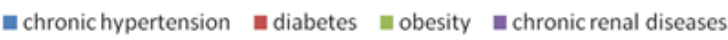

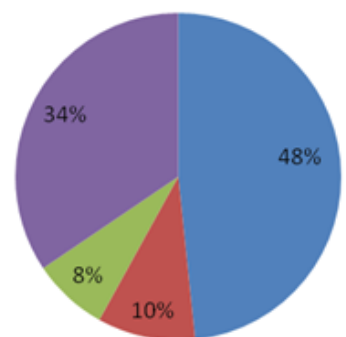

Fig.2. Distribution of pathologic conditions before pregnancy

\begin{tabular}{|l|l|l|l|}
\hline Management of hypertensive disorders in pregnancy & 2012 & 2013 & Total \\
\hline Pregnancy-induced hypertension & $202(9.54 \%)$ & $138(6.28 \%)$ & $340(7.88 \%)$ \\
\hline Caesarean section & $144(56.43 \%)$ & $80(57.97 \%)$ & $194(57.05 \%)$ \\
\hline Early delivery by induction of labour & & & \\
\hline
\end{tabular}

Table 2

MANAGEMENT OF

DELIVERY IN

HYPERTENSIVE

DISORDERS IN

PREGNANCY 


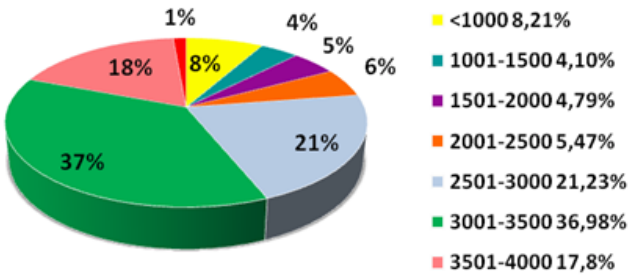

Fig. 4. Distribution of weight at birth

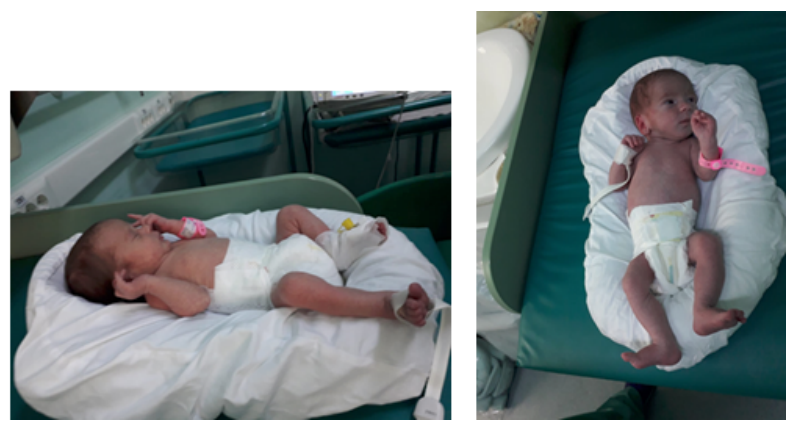

Fig. 5. Premature, 1580g, 13 days.

Clinical observations stated that sleeping quietly and awake and quiet have increased the most when compared with babies out of cocoons. Actually the quality and length of sleep improved which are signs of a better comfort due to physiological flexion realized by positioning the baby into cocoon. Premature babies most likely do not develop this physiological flexion. In this case the cocoon is extremely helpful.

The other parameter, the gastric reflux was reduced very much. Only 8 (18.2\%) babies experienced it.

Maternal medical diseases increase the risk of preeclampsia and, thus, the risk of indicated preterm birth. In a cohort of more than 70 percent white women, Sebire and colleagues [10] noted a decreased frequency of delivery at less than 32 weeks of gestation among women with BMls greater than or equal to 30 compared with that among women with BMIs less than 30 . Those investigators did not differentiate spontaneous from indicated preterm birth.

It is well known that there is an increase in perinatal mortality in pregnancies complicated by pre-gestational diabetes - both type 1 and type 2 diabetes. The magnitude of this risk has decreased dramatically in the past several decades but is still in excess of that found in non- pregestational diabetes pregnancies [11,12].

Hypertensive disorders in pregnancy are significant contributors to maternal and perinatal morbidity and mortality in low-, middle- and high-income countries [13].

In our study, $453(10.5 \%)$ cases of women with different pathological conditions out of 4312 cases were encountered. Most of them (48\%) had a diagnosis of chronic hypertension, followed by chronic renal diseases (34\%). Hypertension developed during pregnancy for both years, happened in $340(7,88 \%)$ pregnant women. The most frequent were the severe forms of hypertension (57.05\%). The incidence of preterm birth babies from the studied period was $11.22 \%$ accounting for 484 cases, of which 12 (8.67\%) resulted from pregnancies that have evolved with different forms of hypertension.

Newborns who need intensive care or invasive maneuvers must adapt to different conditions from intensive care units: exposure to hyper stimulation with lights, alarms and medical maneuvers. A proper positioning of the premature newborn may contribute to the decrease of physiological and motor stress [14].

Positioning of preterm infants as a basic neonatal nursing care include usually supine, prone, side-lying, and head up

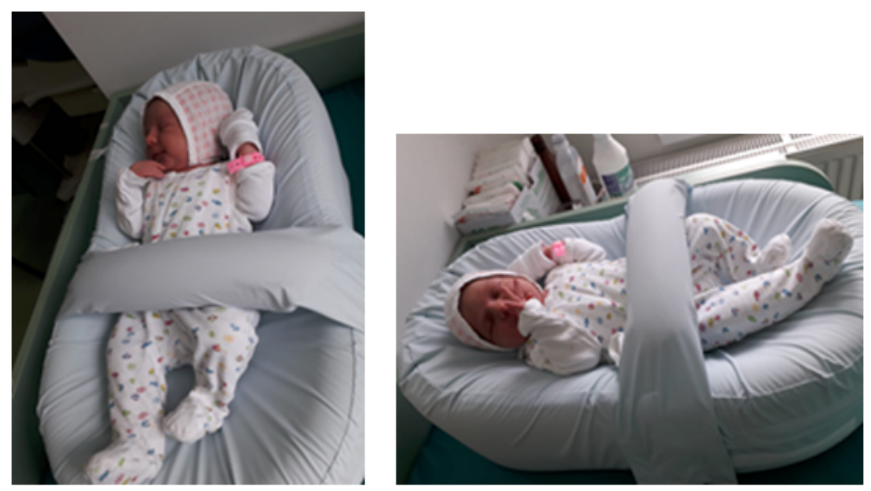

Fig. 6. Newborn, 3280, 1 day

tilted position. Several studies demonstrated a variety of outcomes affected by differentbody positioning of preterm infants. In addition, several studies indicated a strong association between prone sleep position and Sudden Infant Death Syndrome [15,16].

Furthermore, some studies found that preterm infants in a prone position compared to those in a supine position have early motor milestone, decreased energy expenditure, more rapid gastric emptying and less gastric reflux [17, 18].

A comprehensive literature review during 1966-2000 by Monterosso et al. (19) found that the prone position is preferred for very low birth weight infants because it promotes development of pulmonary, cardiovascular, sleep state organizational and gastrointestinal functions. Although research shows advantages and disadvantages for both supine and prone position among preterm infants to their physiological outcomes, there is a trend remains toward keeping preterm infants in a supine position; mainly for ease of observation and handling [19].

As babies develop and grow in the uterus a so called physiological flexion is creating. Premature babies most likely do not develop this physiological flexion. It is common that babies are lying with their arms and legs spread out because of gravity. This is why positioning that promotes physiological flexion can help premature babies to develop the position they had in the uterus.

The flexible polyurethane foam cocoon is assuring a semi-foetal position, in which baby is as if contained and in a slightly curved posture that soothes and reassures him.

In order to analyze the impact of positioning the baby in polyurethane foam cocoon, clinical observations of our study were concerned on sleeping activity and on the presence of gastric reflux. Three consecutive days a number of six states namely sleeping quietly, sleeping in activity, transition when awake and active, awake and quiet, annoyed, and crying were noted to 44 babies positioned in polyurethane foam cocoon comparative with 45 babies positioned in regular hospital conditions. Clinical observations stated that sleeping quietly and awake and quiet have increased the most when compared with babies out of cocoons. Quality as well as length of sleep improved. These are signs of a better comfort due to physiological flexion realized by positioning the baby into cocoon. Considering the gastric reflux this was reduced very much. Only $8(18.2 \%)$ babies experienced it comparatively with 41 babies that were positioned in regular conditions.

\section{Conclusions}

Pathologic pregnancies due to maternal chronic conditions and the hypertension induced during pregnancies can have adverse outcomes on infants, including premature births, intrauterine growth restriction, and neonatal mortality. After delivery the complex care of 
a premature baby is taking into consideration a multitude of actions and medical decisions. Positioning of preterm infants is a basic neonatal nursing care. Positioning the preterm babies in a polyurethane foam cocoon presents many advantages due to creation of physiological flexion position. Quality as well as length of sleep improved together with the drastic reduction of gastric reflux.

\section{References}

1. KERSTEN I, LANGE A. E., JOHANNES P. H., FUSCH C., LODE H., HOFFMANN W, JOCHEN R. T. Chronic diseases in pregnant women: prevalence and birth outcomes based on the SNiP-study, BMC Pregnancy Childbirth. 2014; 14:75, p:1-13. PMCID: PMC3943445PMID: 24552439

2.ESTENSEN M, GUDE E, EKMEHAG B, LOMMI J, BJ ORTUFT O, MORTENSEN S, NYSTROM, ULLA M, SIMONSEN S Pregnancyin heartand heart/lung recipients can be problematic.Scandinavian Cardiovascular Journal, 45(6), 2011, p: 349-353.doi:10.3109/ 14017431.2011.605168

3.DUNLOP AL, JACK BW, BOTTALICO J N, LU MC, JAMESA, SHELLHAAS CS, HALLSTROM LH, SOLOMON BD, FEERO WG, MENARD MK, PRASAD $M R$. The clinical content of preconceptioncare: women with chronic medical conditions. Americanj ournal of Obstetrics \& Gynecology, 199(6), 2008, p:310-327

4.PARKES I, SCHENKER J. G \& SHUFARO Y. Parathyroid and calcium metabolism disorders during pregnancy.Gynecol Endocrinol., 29(6), 2013, p: 515-519. doi:510.3109/09513590.09512012.09754880

5.SIU SC, SERMER M, COLMAN JM, ALVAREZ AN, MERCIER LA, MORTON BC, KELLS CM, BERGIN ML, KIESS MC, MARCOTTE $F$, TAYLOR DA, GORDON EP, SPEARS JC, TAM JW, AMANKWAH KS, SMALLHORN JF, FARINE D, SORENSEN S; Prospective multicenterstudy of pregnancy outcomes in women with heart disease.Circulation, 104(5), 2001, p:515-521. doi:10.1161/hc3001.093437

6.CLUVER C, NOVIKOVA N, KOOPMANS CM, WEST HM. Planned early delivery versus expectant management for hypertensive disorders from 34 weeks gestation to term. Cochrane Database of Systematic Reviews, Issue 1. Art. No.: CD009273., 2017 p:1-76, DOI: 10.1002/ 14651858. CD009273. pub2)

7.PETRICA L; GLUHOVSKI A; AGLUHOVSKI C Proximale tubule disfunction in renal diseases-diagnostic significance of protomics and biomarkers, Revista romana de Medicina de laborator, vol 20, 2012 issue:2, p: 97-107.
8.YOUNG J. Positioning premature babies, nursing preterm babies in intensive care: which position is best? J Neonatal Nurs 1994; September:27-30

9.NODITI G, ZOLER R, NODITI GH, LAZAR F. Synthetic mesh for large ventral hernia repair correlated with evaluation of quality-of-life. A 5 years retrospective study. Rev. Chim. (Bucharest), 69, no. 5, 2018, p:1264-1267.

10.SEBIRE NJ , J OLLY M, HARRIS JP, WADSWORTH J, JOFFE M, BEARD RW, REGAN L, ROBINSON S. Maternal obesity and pregnancy outcome: a study of 287,213 pregnancies in London. Int J Obes Relat Metab Disord. 2001 Aug;25(8):1175-1182.

11.MELAMED N, HOD M. Perinatal mortality in pregestational diabetes. Int] Gynaecol Obstet 2009; 104: P: 20-24. [PubMed]

12. EIDEM I, VANGEN S, HANSSEN KF, VOLLSET SE, HENRIKSEN T, J ONER G, STENE LC. Perinatal and infant mortality in term and preterm births among women with type 1 diabetes. Diabetologia 2011; 54: p:2771-2778. [PubMed]

13.KHAN KS, WOJ DYLA D, SAY L, GULMEZOGLU AM, VAN LOOK PF. WHO analysis of causes of maternal death: systematic review. Lancet 2006;367(9516), p:1066-1074.

14.CHEN CM, LIN KH, SU HY, LIN MH, HSU CL. Improving the provision of nesting and positioning for premature infants by nurses in neonatal intensive care units]. Hu Li Za Zhi 2014;61(2Suppl):p: 41-49.

15.WILLINGER M, HOFFMAN HJ, WU KT, HOU J R, KESSLER RC, WARD SL, KEENS TG, CORWIN MJ. Factors associated with the transition to nonprone sleep positions of infants in the United States. J AMA 1998;280 (4), p:329-335.

16.MYERS MM, FIFER WP, SCHAEFFER L, SAHNI R, OHIRA-KIST K, STARK RI, SCHULZE KF. Effects of sleeping position and time after feeding on the organization of sleep/awake states in prematurely born infants. Sleep 1998;21(4), p:343-349.

17.DAVIS BE, MOON RY, SACHS HC, OTTOLINI MC. Effects of sleep position on infant motor development. Pediatrics 1998,102(5), p: 11351139 .

18.EWER AK, JAMES ME, TOBIN J M. Prone and left lateral positioning reduce gastro-oesophageal reflux in preterm infants. Arch Dis Child Fetal Neonatal Ed 1999;81, p201-205.

19.MONTEROSSO L, KRISTJANSON L, COLE J. Neuromotor development and physiologic effects of positioning in very low birth weight infants. J Obstetr Gyneco Neonat Nurs 2002;31(2), p:138-146.

$\overline{\text { Manuscript received: } 21.08 .2018}$ 